\title{
Histopathological study of solitary nodules of thyroid
}

\author{
Khadilkar $\mathbf{U N}^{1}$, Maji $\mathbf{P}^{2}$ \\ ${ }^{1}$ Professor of Pathology, Kasturba Medical College, Mangalore, ${ }^{2}$ Consultant Pathologist, Ramkrishna Road, Ranisagar \\ [North], P.O.Dt. Burdwan, West Bengal
}

\begin{abstract}
Objective: To determine the incidence of various thyroid disorders manifesting as Solitary Thyroid Nodule and also to evaluate the histomorphology of the lesions.

Materials and methods: Hundred specimens of Solitary Thyroid Nodules were studied for gross characteristics, microscopic features, age and sex incidence.

Results: Of the 100 cases of Solitary Thyroid Nodules, 66\% were non neoplastic and 34\% were neoplastic. Among the neoplasms, 21\% were malignant and 13\% were benign. The age incidence ranged from 20-50 years for non neoplastic lesions and 20-40 years for neoplasms. A female preponderance was seen for both non neoplastic and neoplastic conditions. The solitary nodules involved the right side of the thyroid more commonly than the left. Involutional colloid nodule was the predominant type of solitary nodule (52\%). Among the malignant neoplasms, papillary carcinoma was the commonest solitary nodule (13\%). One case each of hyalinising trabecular adenoma, columnar cell variant of papillary carcinoma and medullary carcinoma unusually presenting as solitary nodules were encountered in the present study.

Conclusion: Histomorphologic evaluation of Solitary Thyroid Nodules presenting without a background setting of multinodular goiter is challenging and mandatory as the diagnoses ranges from the common non neoplastic lesions like involuting nodules to the rare neoplastic conditions like medullary carcinoma.
\end{abstract}

Key words: Solitary Thyroid Nodule morphology, involuting nodule, medullary carcinoma

$\mathrm{T}$ he thyroid nodule has been the subject of vigorous controversy with divergent opinions and different connotations, when considered by the thyroid clinician, the thyroid surgeon or the thyroid pathologist. The primary concern is the biologic behaviour of benignancy versus malignancy in a nodule so that the operative approach can be aptly modified. Solitary nodule thyroid (SNT) is defined as a discrete palpable mass in a gland that is otherwise clinically apparently normal. Virtually any disease can present as SNT and a large number of thyroid nodules diagnosed clinically as solitary are actually hyperplastic nodules in multinodular goitres. Though SNT is commoner in women, ${ }^{1,2,3,4}$ malignancy in SNT is commoner in men ${ }^{5}$. The younger the patient with a thyroid nodule, the greater the likelihood of it being malignant; ${ }^{5}$ the carcinoma in younger patients is more often of a lower grade than in older patients who tend to have a more aggressive form of malignancy ${ }^{3}$.

\section{Materials and methods}

One hundred specimens of SNT, received in the department of Pathology over a period of two years were examined grossly for size, consistency, colour, capsule, calcification, cysts, haemorrhage, necrosis, colloid and papillary projections. Multiple sections were taken for routine paraffin processing and study by Haematoxylin $\&$ Eosin stain.

\section{Results}

Sixty six percent (66 cases) of SNTs were non neoplastic and $34 \%$ were neoplastic. Fifty two percent of the non neoplastic lesions were involutional colloid nodules, $10 \%$ adenomatous nodules, $1 \%$ hyperplastic dominant nodule and 3\% colloid cysts. Among the neoplastic lesions, $13 \%$ were follicular adenomas, $7 \%$ follicular carcinoma, $13 \%$ papillary carcinoma and $1 \%$ medullary carcinoma (Table 1). The age incidence for SNTs ranged from 10 to 72 years; the non neoplastic lesions were seen over a wider range than the neoplastic ones, which were commoner between 20 and 40 years (Table 1).

The peak incidence of involutional nodule was between 41- 50 years and adenomatous nodule was found commonly between 21 - 30 years. The peak incidence

Correspondence

Dr. Urmila N. Khadilkar

Professor of Pathology

Kasturba Medical college

Mangalore-575001

Karnataka state, India

E-mail: urmilank@yahoo.co.in 
of follicular adenoma and carcinoma was in the $3^{\text {rd }}$ and $4^{\text {th }}$ decade respectively. The SNTs were commoner in females with a F: M ratio of 6.1:1; it was F:M 8:1 for benign lesions and F:M 5:1 for malignant lesions (Table $1)$.

Gross findings: Out of the 100 specimens, eight were resected solitary nodules and the remaining were partial thyroidectomy, hemithyroidectomy and lobectomy specimens.

Capsule: Majority of the involuting nodules and adenomatous nodular hyperplasia were well circumscribed and unencapsulated colloid nodules (Figure1). Among the neoplasms, majority of the adenomas were encapsulated and most of the carcinomas were unencapsulated and circumscription was observed in majority of papillary carcinomas. The single medullary carcinoma in the present study was completely encapsulated. (Table 2).

Cystic change: Other than colloid cyst, cystic change was commonest in involuting nodules, followed by adenoma, adenomatous nodule and papillary carcinoma (Table 2).

Microscopic findings: The involuting nodules showed colloid-filled follicles of different sizes, lined by inactive epithelium. Some of the follicles showed papillary folds of the lining epithelium, cystic change and Hurthle cell lining. Areas of fibrosis, calcification, aggregates of foamy macrophages, lymphocytic infiltration and giant cell reaction were seen in the stroma.

Only one of the SNTs was found to be a hyperplastic dominant nodule in which the surrounding parenchyma showed microscopic nodules and lymphocytic thyroiditis. The adenomatous hyperplastic nodules showed scanty colloid in the follicles and degenerative fine needle aspiration induced changes in a few cases. The colloid cysts showed a thick and fibrous cyst wall

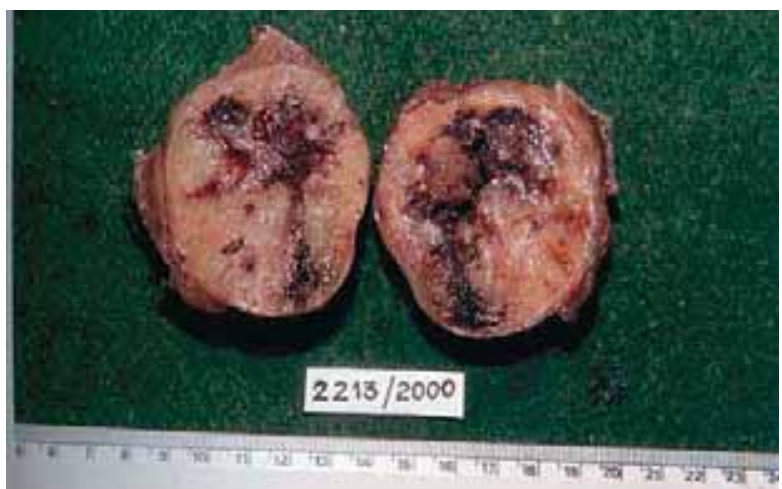

Fig 1: Solitary Involutional Nodule without a capsule and with a variegated cut surface. lined by colloid filled follicles and compressed thyroid tissue outside the cyst. The contents of the cyst were fluid with haemosiderin macrophages and one of the cysts was lined by granulation tissue.

Among the neoplastic nodules, follicular adenomas had a thin complete capsule and the predominant pattern was normofollicular, followed by macro and microfollicular. One each of fetal and embryonal type was seen. Degenerative changes and peritumoral lymphocytic infiltration were observed in the neoplasms. In one case there was a thick capsule surrounding the adenoma resembling that seen in malignant neoplasms, but no vascular or capsular invasion was seen.

There were seven cases of follicular carcinomas, six of which had an incomplete capsule which was thick and irregular. Capsular and vascular invasion was seen in five cases and transcapsular spread in one. In another well differentiated microfollicular carcinoma, a satellite nodule was seen outside the capsule with metastasis to the thoracic wall. The associated changes seen in the neoplasms were Hurthle cell mataplasia, subcapsular calcification, cystic change and peritumoral lymphocytic infiltration.

Majority of the papillary carcinomas were well circumscribed (Figure 2) and papillae were seen grossly in two cases. Microscopically a range of histologic patterns like follicular variant (2), macrofollicular variant (2), cystic variant (1), columnar cell variant (1), and encapsulated variant (2) were observed. Peritumoral lymphocytic infiltration was seen in many of the neoplasms and in some there was formation of lymphoid follicles. One case was associated with Hashimoto's thyroiditis. In three cases there was intrathyroidal spread with nodules outside the main neoplasm; there was extension to soft tissue in three others. There was one case of well encapsulated medullary carcinoma with rich stromal vascularity, hyalinization and abundant birefringent amyloid (Figure 3).

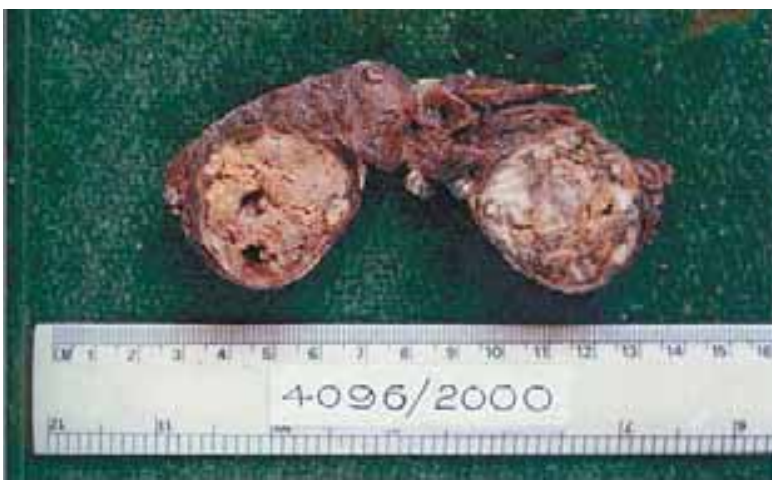

Fig 2: Well circumscribed Nodule of Papillary Carcinoma. 


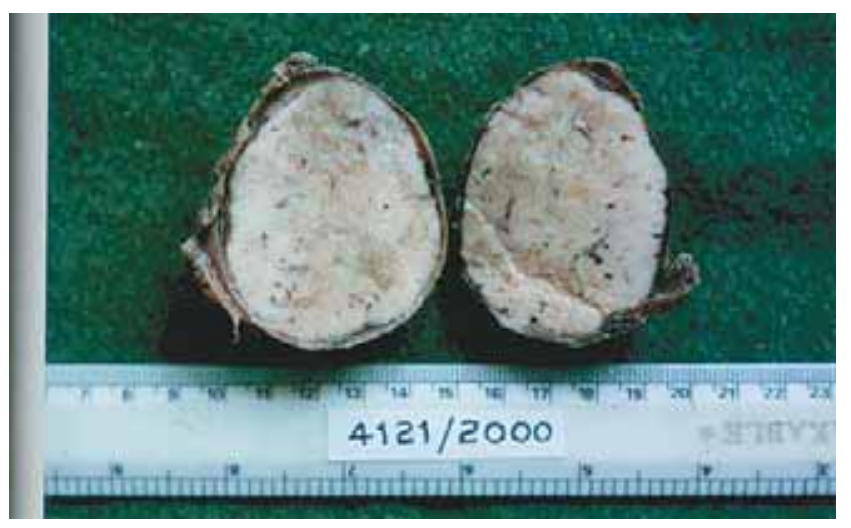

Fig 3: Encapsulated Solitary Nodule of Medullary Carcinoma.

Table 1: Distribution of cases of SNT

\begin{tabular}{|l|c|c|c|c|}
\hline Lesions & No. of cases & Peak incidence & No.of women & No. of men \\
\hline Non neoplastic & 52 & $41-50$ years & 45 & 7 \\
Involutional colloid nodule & 10 & $21-30$ years & 9 & 1 \\
Adenomatous nodule & 1 & 72 years & & 1 \\
Hyperplastic dominant nodule & 3 & $25-45$ years & 3 & - \\
Colloid cyst & & & & \\
& & & & \\
Neoplastic & 13 & $21-40$ years & 13 & 2 \\
Follicular adenoma & 7 & $31-40$ years & 5 & 3 \\
Follicular carcinoma & 13 & $31-40$ years & 10 & - \\
Papillary carcinoma & 1 & 40 years & 1 & \\
Medullary carcinoma & & & \\
\hline
\end{tabular}

Table 2: Capsule and cystic changes in SNT

\begin{tabular}{|l|c|c|c|c|c|c|}
\hline SNT & $\begin{array}{c}\text { Complete } \\
\text { capsule }\end{array}$ & $\begin{array}{c}\text { Incomplete } \\
\text { capsule }\end{array}$ & $\begin{array}{c}\text { Well } \\
\text { circumscribed }\end{array}$ & $\begin{array}{c}\text { Poorly } \\
\text { circumscribed }\end{array}$ & $\begin{array}{c}\text { Cystic } \\
\text { change }\end{array}$ & Total \\
\hline Involutional nodule & 13 & 1 & 29 & & 19 & 52 \\
\hline $\begin{array}{l}\text { Adenomatous } \\
\text { nodule }\end{array}$ & 5 & & 5 & & 3 & 10 \\
\hline Hyperplastic nodule & & & & & 3 & 3 \\
\hline Colloid cyst & 3 & & 5 & & 5 & 13 \\
\hline Follicular adenoma & 8 & & 5 & & 13 & 7 \\
\hline $\begin{array}{l}\text { Follicular } \\
\text { carcinoma }\end{array}$ & 1 & 1 & 8 & & & 13 \\
\hline Papillary carcinoma & 4 & 1 & & & & 1 \\
\hline $\begin{array}{l}\text { Medullary } \\
\text { carcinoma }\end{array}$ & 1 & & & & & 13 \\
\hline
\end{tabular}




\section{Discussion}

'Dignus Vindice Nodus' - the latin origin of the word 'nodus' is defined as 'a complication requiring divine intervention ${ }^{5}$. Any clinical impression regarding the nature of the pathologic process involving a thyroid nodule is open to error as indicated by a study of preoperative diagnostic ability ${ }^{6}$. Thyroid nodules are difficult to classify and their behaviour is nearly impossible to predict since virtually any thyroid disease can present as a $\mathrm{SNT}^{7}$.

Clinically apparent thyroid nodule is age dependent, being quite low in children and surprisingly high in older patients. Papillary carcinoma is seen in younger age group when exposed to radiotherapy at an early age. A SNT presenting after 50 years of age is primarily neoplastic ${ }^{7}$. In the present study all the follicular adenomas were seen below the age of 45 and the neoplasms seen above 50 years were either follicular or papillary carcinomas.

The incidence of SNT is more in females than in males but malignancy in SNT is more in males than in females. Hoffman et $\mathrm{al}^{5}$ found the maximum numbers of carcinomas in the 202 cases of SNT's studied, with the majority being papillary carcinomas $(28.7 \%)$ followed by follicular carcinoma and hurthle cell carcinoma; the percentage of carcinomas was more in men $(31.4 \%)$ than in women $(27.8 \%)$. In a study of 148 patients Robinson et $\mathrm{al}^{1}$ found SNT's in $80.4 \%$ women and in $19.6 \%$ men. In the present study, a female preponderance was seen in both the non neoplastic and neoplastic lesions with the majority of follicular and papillary carcinomas affecting women and all the adenomas were seen only in women.

Many of the clinically apparent SNTs are seen in a clinical setting of multinodular goiter and such cases were not included in the present study. Encapsulation of the solitary nodule is important in that complete and incomplete capsulation differentiates follicular adenoma from carcinoma ${ }^{3}$. Adenomas are characteristically surrounded by a generally thin capsule that is grossly and microscopically complete. In the present study thick capsule was seen in one adenoma and thin capsule in two follicular carcinomas; subcapsular calcification was associated with one carcinoma in addition to the capsular and vascular invasion. Majority of the non neoplastic nodules showed dense surrounding stromal fibrosis mimicking a capsule. Kaleem \& Davila ${ }^{8}$ encountered two cases of hyalinising trabecular adenomas which were nodular and surrounded by a thin fibrous capsule. In the present study, there was a hyalinising trabecular variant of adenoma which was encapsulated and showed the distinctive histology of nests of cells separated by hyaline stroma without any secondary changes.
Liechty et al ${ }^{9}$ noticed that there was a predilection for benign and malignant nodules to occur in the right lobe and Robinson et al ${ }^{1}$ also found that in $40 \%$ cases the nodules were located in the right lobe. SNTs were seen more commonly on the right side of the thyroid, in the present study. Cystic change was commonly associated with involutional nodules, follicular adenoma, and papillary carcinoma, in the order of occurrence. Papillary excrescences were seen grossly as well as microscopically in three involutional nodules and in hyperplastic nodule with the papillae facing the lumen of the cystic follicles; in papillary carcinoma the distribution of the papillae was random. The lymphocytic infiltration was often focal, without formation of follicles in some of the involuting nodules whereas it was more extensive, admixed with plasma cells and seen at the infiltrating edges of the tumour in papillary carcinoma. Whether the lymphocytes represent an immunological response is unclear. The incidence of coexistent Hashimoto's thyroiditis seen in one case each of colloid nodule and papillary carcinoma in the present study is unknown since both are common lesions and the finding may be only fortuitous. However if the thyroiditis is seen solely in the vicinity of the tumour with sparing of the uninvolved gland, then the possibility of a predisposing condition may be considered. In the present study, in papillary carcinoma intrathyroidal spread was most common (three cases), followed by parathyroid (two cases) and lymph nodes (one case). Extrathyroidal metastasis to the adjacent soft tissue and chest wall was rarely seen in papillary and follicular carcinomas (one case respectively); wide capsular invasion was the most significant finding in follicular carcinoma (five cases); follicular carcinoma with a satellite nodule away from the tumour and in the thyroid parenchyma was associated with metastasis to soft tissue in one case, which may suggest the possibility of a vascular mode of spread of follicular carcinoma, in the thyroid as well as outside. In the present study there was one case of columnar cell variant of papillary carcinoma and another case of encapsulated medullary carcinoma, both of which presented unusually as SNT.

Rarely, metastasis to the thyroid can present as SNT and renal cell carcinoma presenting as SNT has been reported ${ }^{10}$. In recent years Das et $\mathrm{al}^{11}$ studied 100 cases of solitary nodules and found only one case of papillary carcinoma; the remaining 99 cases were colloid nodules, cysts, adenomas and subacute thyroiditis.

\section{Conclusion}

Since the finding of a thyroid nodule is a common clinical problem and the proportion of such nodules that prove to be malignant is small, investigations are of immense help to corroborate with the clinical and morphological findings. Fine needle aspiration and 
biopsy has been shown to establish a correct diagnosis in a substantial number of cases before resorting to surgery. Examination of tissue by frozen section during surgery is often unhelpful and it's use is debatable. Thyroid lobectomy then becomes the only alternative procedure in order to reach a correct diagnosis for SNT by histomorphologic analysis.

\section{References}

1. Robinson E, Horn Y, Hochmann A. Incidence of cancer in thyroid nodules. Surg Gynecol Obstet 1966;123:1024-6.

2. Knowlson GTG. The Solitary thyroid nodule. Br J Surg 1971;58:253-4.

3. Brown L, Kautounis S. The Thyroid Nodule. Am J Surg 1975;129:532-6.

4. Liechty RD, Stoffel PT, Zimmerman DE, Silverberg SG. Solitary Thyroid Nodules. Arch Surg 1977;112:59-61.

5. Hoffman GL, Thompson NW, Heffron C. The Solitary Nodule. Arch Surg 1972;105:379-85.
6. Bartels EC, Bell GO, Geokas MC. Evaluation of the Thyroid Nodule. Surg Clin N Amer 1962;42:655.

7. Mazzaferri EL, Santos EJ, Rofagha KS. Solitary Thyroid Nodule- Diagnosis and management. Med Clin N Amer 1988;72(5):1177-201.

8. Liechty RD, Graham M, Freemeyer P. Benign Solitary Thyroid Nodule. Surg Gynecol Obstet 1965;121:571-3.

9. Kaleem Z, Davila RM. Hyalinising Trabecular Adenoma of the Thyroid: A report of two cases with cytologic, histologic and immunohistochemical findings. Acta Cytologica 1997;41(3):883-8.

10. Chen WR, Jeoh LC, Ong BH. Renal Cell Carcinoma presenting as a Solitary thyroid Nodule. Ann Acad Med Singapore 1981;10(2):229-32.

11. Das AB,Alam MN,Haq SAetal. Solitary Thyroid Nodule- A study of 100 cases. Bangladesh Med Res Council Bull 1996;22:12-8. 